\title{
Changing demands made by senile dementia on the National Health Service
}

\author{
J A STILWELL, ${ }^{1}$ CHRISTINE HASSALL, ${ }^{2}$ AND SUE ROSE 2 \\ From the Health Services Research Centre, ${ }^{1}$ and the Department of Psychiatry, ${ }^{2}$ University of Birmingham, \\ Birmingham, UK
}

SUMMARY In 1976 and 1981 two studies were undertaken to identify the numbers of elderly severely mentally infirm patients receiving care in a range of institutions in Worcestershire and to examine the appropriateness of the special units planned for them. The numbers of planned places matched the totals of patients in care but the nature of the provision was wrong. The new units were planned for able bodied but demented patients, with a relatively low staff/patient ratio. The number of these patients had fallen by one third, being replaced by patients who needed heavy physical nursing care. The new units would not therefore be able to fulfil their planned role of providing cheaper care than did the geriatric or psychiatric hospitals.

In 1972 the Department of Health recognised that no existing institutions catered specially for the needs of those patients newly termed "elderly severely mentally infirm." This group is formally defined as "elderly patients with severe dementia, but not suffering from other significant physical disease or illness,"1 and special physical provision was thought appropriate for this group where "...their continuing care will not entail the wide range of diagnostic and treatment facilities of the general hospital. Their need is rather for nursing supervision by group observation, with individual nursing attention as occasion arises ...". ${ }^{2}$ The recommended residential provision was $2 \cdot 5-3$ beds per 1000 population aged 65 and over in new ESMI units within the NHS. These units were intended to take over from existing mental illness, geriatric, and cottage hospitals and local authority homes the responsibility for the care of people in this group. When, therefore, Worcester Health District planned to replace its existing mental illness services over a period of about 10 years (1973-83) it incorporated in its scheme, known as the Worcester Development Project, ${ }^{3}$ one ESMI unit. The unit was initially considered in 1975 and a total of 48 beds was planned-well below the guideline figures. A survey was carried out of all hospitals in the Worcester Health District and all local authority residential homes in order to locate everyone aged 65 and over who was severely mentally infirm and receiving institutional care. The population of the Worcester
Health District was then 216000 , of whom 31000 were aged 65 and over.

\section{Method}

In the psychiatric hospital (480 beds, 290 occupied by people aged 65 and over) and geriatric hospitals ( 283 beds), where most cases were expected, a simple screening test ${ }^{4}$ was administered to all patients aged 65 or over who gave their permission. Those who had been patients or residents for less than one month were omitted in order to minimise the risk of including patients whose confusion was short term and not a true dementia. Five hundred and two patients were interviewed.

A simple survey of nursing dependency was included in order to identify demented people in hospitals who needed little physical nursing care and those in local authority homes who were receiving considerable nursing care.

The social services department made the stringent requirement that their own central supervisory staff should obtain the informed consent of any residents interviewed in local authority homes, and it was decided, in order to save time, to test the agreement between the assessment of residents by the senior residential care staff and by the formal method used in the hospitals. At two homes, therefore, covering 57 out of a total of 638 residential places, the care staff were asked to classify residents according to whether or not they were severely demented. The 
screening test was administered (without the knowledge of the care staffs' assessments) and agreement was $100 \%$. At the remaining homes, therefore, information was gathered from the senior officers and care staff.

Two groups were then excluded. Firstly, anyone suffering from a serious physical illness requiring constant nursing care was excluded, since Departmental guidelines allocate such cases to geriatric hospitals. Secondly, those who had grown old in the mental hospital were excluded to make it reasonable to use the existing prevalence as a guide for the future by removing the influence of factors that no longer exist-in this case those factors causing institutionalisation.

All patients, therefore, who had been in the mental illness hospital for five years or longer, or who, although their most recent admission date was less than five years before the survey, had had previous admissions accumulating at least five years, were excluded.

\section{Results}

In the 1976 survey we discovered 129 people, already in care, who would have been qualified for admission to ESMI units (table 1).

In 1976 the number of planned beds was increased to 60 and by 1980 a second 24 bed unit was proposed. By 1981, when the first ESMI unit, now with 68 beds, was under construction, the over 65 population had increased from 31000 to $33000,(6 \cdot 45 \%)$, and this increase was concentrated almost exclusively in the over 75s. Although no single study gives a definitive estimate of the prevalence of senile dementia, all authorities agree that prevalence increases rapidly over 75 , rising to over $20 \%$ of the over 80 s.

We therefore repeated our survey to see whether the provision would now be satisfactory or whether once again plans had been overtaken by events. Table 2 shows the results of the second survey, carried out at the end of 1981 .

\section{Discussion}

Whereas the total number of people suffering from severe dementia has hardly altered, there has been a considerable shift from the relatively able bodied group to the group which needs considerable physical nursing. The official provision of ESMI beds for this health district would be between 80 and 100 and at least 92 are planned. This is close to the number of patients (85) found in the second survey who satisfy the criteria for admission to an ESMI unit-much closer than the number found six years ago-and although opening the new ESMI units will not
Table 1 Location and nursing needs of severely demented patients: * Worcester Health District, 1976

\begin{tabular}{llcc}
\hline & $\begin{array}{l}\text { Severely demented } \\
+ \text { heavy }\end{array}$ & $\begin{array}{l}\text { Severely demented, } \\
\text { not heavy nursing }\end{array}$ & Total \\
\hline Mental illness hospital & 18 & 43 & 61 \\
Geriatric hospital & 70 & 20 & 90 \\
Local authority homes & - & 66 & 66 \\
Total & 88 & 129 & 217 \\
\hline
\end{tabular}

*Excludes those with more than five years as an inpatient at mental illness hospital.

Table 2 Location and nursing needs of severely demented patients: Worcester Health District, 1981

\begin{tabular}{lccc}
\hline & $\begin{array}{l}\text { Severely demented } \\
+ \text { heavy nursing }\end{array}$ & $\begin{array}{l}\text { Severely demented, } \\
\text { not heavy nursing }\end{array}$ & Total \\
\hline Mental illness hospital & 42 & 23 & 65 \\
Geriatric hospital & 56 & 13 & 69 \\
Local authority homes & 35 & 49 & 84 \\
Total & 133 & 85 & 218 \\
\hline
\end{tabular}

significantly increase the total residential provision for such patients it seems as if it will at least cater for the number already in care.

The reduction in the number of able bodied ESMI and the increase in the number of physically dependent ESMI-a 21\% swing-may be accounted for in two ways. Firstly, the increase in the population of the very old and, secondly, the more active community nursing policy of the local geriatricians appointed since the first survey. This latter factor may also be connected with what may be seen as the most disturbing finding of this survey-the enormous shift of the physically dependent from geriatric hospital to local authority old people's homes. In 1976 we found nobody in local authority old people's homes, ${ }^{*}$ with a total of 638 places, who was both demented and needed heavy nursing care (heavy nursing care is care that often needs two rather than one care assistant or nurse). In 1981 we found 35 . The number of patients in this category in hospital had fallen from 70 to 56 .

ESMI units were originally intended to relieve the emotional and psychological burden on relatives and local authority home care staff of elderly people whose dementia caused behaviour problems but who were physically robust. The units were intended to be cheaper than hospitals, both in terms of staffing and equipment.

"We are unable to say whether a similar increase had been experienced by voluntary and private old people's homes (about 390 places in 1981) but it is the impression of the social services department (S Gosling, private communication) that the prevalence of dementia is similar, and that there are more people who need heavy nursing care than are in local authority homes. 
Practice is already showing that these intentions were unrealistic. Units now designated as ESMI are staffed at the same level as psychiatric hospital wards. The growing problem is not that of the mentally confused but physically well; it is the increase in the number of the mentally confused and physically frail, for whom neither ESMI unit nor old people's home were intended.

We are grateful to many people connected with medical and social services in Worcestershire for helping us in this study. We also thank Mrs L Woods and Mrs $M$ Williams for their valuable help.

\section{References}

${ }^{1}$ Department of Health and Social Security. Guidelines for regional authorities. London: HMSO, 1972.

${ }^{2}$ Department of Health and Social Security. Better service for the mentally ill. London: HMSO, 1975. (Para 4.13.)

${ }^{3}$ Stilwell JA, Hassall C. In: McLachlan G, ed. Probes for health. London: Oxford University Press, 1975.

4 Blessed G, Tomlinson BE, Roth M. Association between quantitative measures of dementia and of senile changes in the cerebral grey matter of elderly subjects. $\mathrm{Br} \mathrm{J}$ Psychiatry 1968; 114: 797-811. 